\title{
sciendo
}

\section{EFFECT OF TWO COOLING FREQUENCIES ON RESPIRATION RATE IN LACTATING DAIRY COWS UNDER HOT AND HUMID CLIMATE CONDITIONS*}

\author{
Severino Pinto ${ }^{1,2}$, Gundula Hoffmann ${ }^{1 \bullet}$, Christian Ammon ${ }^{1}$, Wolfgang Heuwieser ${ }^{3}$, Harel Levit ${ }^{4}$, \\ Ilan Halachmi ${ }^{4}$, Thomas Amon ${ }^{1,2}$
}

\begin{abstract}
${ }^{1}$ Department of Engineering for Livestock Management, Leibniz Institute for Agricultural Engineering and Bioeconomy - ATB, Max-Eyth-Allee 100, 14469 Potsdam, Germany

${ }^{2}$ Institute of Animal Hygiene and Environmental Health, Free University Berlin, Robert-von-Ostertag 7-13, 14163 Berlin, Germany

${ }^{3}$ Clinic for Animal Reproduction, Free University Berlin, Königsweg 65, 14163 Berlin, Germany ${ }^{4}$ Precision Livestock Farming Laboratory, Agricultural Research Organization - The Volcani Center ARO, HaMaccabim Road 68, 7505101 Rishon LeZion, Israel

•Corresponding author: ghoffmann@atb-potsdam.de
\end{abstract}

\begin{abstract}
The aim of this study was to evaluate the effects of evaporative cooling at two different frequencies per day on the respiration rate (RR) of lactating dairy cows, considering cow-related factors. Twenty multiparous Israeli Holstein dairy cows housed in a naturally ventilated cowshed were divided randomly into two treatment groups. The cows of both groups were exposed to 3 or 8 cooling sessions per day ( $3 \times 1$ cool vs. 8xcool, respectively). The RR was observed hourly, with a maximum of 12 measurements per day. Body posture (standing vs. lying) was simultaneously documented. Milk yield was recorded daily. Coat color was determined from a digital photograph. The RR of standing and lying cows was lower in the 8xcool group $(60.2$ and 51.6 breaths per $\min (\mathrm{bpm})$, respectively) than in the $3 \times 1$ cool group $(73.1$ and $65.6 \mathrm{bpm}$, respectively). For each increment of five kilograms of milk produced, RR increased by one bpm, and the RR of cows in early days in milk (DIM) was $12.3 \mathrm{bpm}$ higher than that of cows in late DIM. In conclusion, eight cooling sessions per day instead of three lead to a RR abatement in heat-stressed cows under hot conditions, and cowrelated factors directly impact the RR during heat stress assessment.
\end{abstract}

Key words: heat stress, evaporative cooling, cow-related factors, precision livestock farming (PLF), animal welfare

Heat stress in dairy cows is considered an important problem hindering production, reproductive performance, and animal welfare (Kendall et al., 2007). These

*Work financed from: OptiBarn project of the FACCE ERA-NET Plus Initiative Climate Smart Agriculture and scholarship from the Coordination for Improvement of Higher Education Personnel CAPES (Brazil). 
negative effects are relevant for dairy cows with high genetic merit, which are considered to be more sensitive to heat stress (Kadzere et al., 2002). Cows with high milk yield performances produce more body heat as a result of metabolic processes (Hahn, 1999; West, 2003). Respiration rate (RR) is one possibility to regulate the body temperature under heat load (Bernabucci et al., 2010; Polsky and von Keyserlingk, 2017) through endogenous heat loss via the respiratory tract (Legates et al., 1991). Therefore, RR is a sensitive indicator to assess heat load in dairy cows (Tucker et al., 2008; Galán et al., 2018). When cattle are exposed to fluctuating ambient temperatures, the RR is consistently affected with little or no lag period. RR is a simple parameter to monitor without costly equipment (Brown-Brandl et al., 2005).

The typical summer season in the coastal plain of Israel is characterized by stable hot and humid weather with minor fluctuations (Moallem et al., 2010). In the last 30 years, evaporative cooling (forced ventilation and sprinklers) was implemented in Israel to alleviate heat stress in dairy cows in open cowsheds (Berman et al., 1985). Evaporative cooling provides a short term cooling effect (Valtorta and Gallardo, 2004; Kendall et al., 2007). Above $35^{\circ} \mathrm{C}$, evaporative cooling becomes the only method for heat dissipation in dairy cows to maintain homeostasis (Burgos et al., 2007). These methods enable high milk production in hot regions by improving heat release (Ortiz et al., 2015; Fournel et al., 2017).

Susceptibility of cows to heat stress is individual and influenced by various factors related to the cow (Gaughan et al., 2000; Kadzere et al., 2002). Body posture is a relevant factor to be considered in cows under heat stress conditions. Lying cows may show heat stress earlier, even with a lower temperature threshold (Berman, 2005; Herbut and Angrecka, 2018). In a recent study, we observed a higher RR in lying cows than in standing cows at a temperature-humidity index (THI) below 80 (Pinto et al., 2019).

Some authors documented that milk yield (Hahn, 1999) and days in milk (Sharma et al., 1983) are associated with heat metabolic increase and, consequently, heat load in dairy cows (Kadzere et al., 2002; West, 2003). The influence of coat color, length and density of hair have also been investigated in recent years in dairy cows under heat stress conditions (Maia et al., 2005; Kendall et al., 2007; Tucker et al., 2008). Dark cows were more susceptible to absorbing solar radiation but also demonstrated higher rates of heat loss than cows with light coats (Maia et al., 2005; Tucker et al., 2008), because white coat cows presented longer hairs $(15.13 \pm 0.16 \mathrm{~mm})$ and a higher density $\left(1296 \pm 21\right.$ hairs $\left./ \mathrm{cm}^{2}\right)$ than the cows with black coats $(12.97 \pm 0.16$ $\mathrm{mm}$ and $921 \pm 21$ hairs $/ \mathrm{cm}^{2}$, respectively; Maia et al., 2005). In contrast, when considering cooled cows, the coat color did not influence the RR (Kendall et al., 2007).

Several studies have demonstrated the effect of evaporative cooling, considering different frequencies of heat abatement. The frequency varied from two (Valtorta and Gallardo, 2004) to four (Avendano-Reyes et al., 2010), five (Flamenbaum et al., 1986), eight (Honig et al., 2012) and nine (Her et al., 1988) cooling sessions per day. However, these studies evaluated RR of cow solely twice per day or once per week which increase the uncertainty of heat load assessment. In addition, previous studies did not consider the immediate effect on cooled animals, both when the cooling management was being applied and after the cooling session. Therefore, the objective of 
this study was to evaluate the effect of two different cooling frequencies on the RR of lactating dairy cows, considering cow-related factors. Specifically, we hypothesized that cows with three cooling sessions per day would have a higher RR than cows cooled eight times per day. Differences in RR could also be observed among the phases before, during and after cooling. Furthermore, we hypothesized that body posture, milk yield, days in milk (DIM) and coat color would influence the RR.

\section{Material and methods}

\section{Animals, housing and management}

The study was conducted on the research dairy farm of the Agricultural Research Organization, Volcani Center in Rishon Letsiyon, Israel. The experiment was carried out during summer, on 25 measurement days from July to August 2016. A total of 20 lactating Israeli Holstein dairy cows from a group of 30 cows in the barn, second to seventh lactation were included in the trial. The cows were housed all together (both treatment groups) in one single naturally ventilated cowshed. The cowshed floor was a dry manure (elsewhere known as "compost barn") aligned in a NW-SE

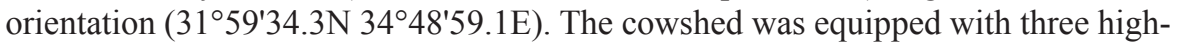
volume, low-speed ceiling fans (730 $\mathrm{cm}$ in diameter; capacity: 722,000 $\mathrm{m}^{3}$ of air/h), which worked continuously day and night. The cowshed was divided by light mobile fences. Both groups of cows were exposed to exactly the same conditions and the same farm handling and housing conditions, the only different parameter was the desired experimental parameter, the cooling frequency. The cows were assigned randomly to two different cooling frequencies per day i.e., with three cooling sessions per day $(3 \times$ cool; $n=10)$ and with eight cooling sessions per day $(8 x \operatorname{cool} ; n=10)$.

The cooling sessions were implemented in the waiting yard of the milking parlor, which is located about $20 \mathrm{~m}$ from the cowshed, the path from the cowshed to the cooling yard was $70 \mathrm{~m}$. The cooling area had a well-drained concrete floor and had dimensions of $12 \times 9 \mathrm{~m}\left(108 \mathrm{~m}^{2}\right)$, with approximately $3.6 \mathrm{~m}^{2} \mathrm{cow}^{-1}$. The cooling area was equipped with three large side fans $\left(2 \mathrm{~m}\right.$ in diameter; capacity: $120,000 \mathrm{~m}^{3}$ of air $/ \mathrm{h}$ each) to produce airflow perpendicular to the cows body surface $(10.6 \mathrm{~m} / \mathrm{s} \mathrm{air}$ velocity nearby of the fan). A total of 30 sprinklers $(720 \mathrm{~L} / \mathrm{h}$ ) were fixed $2.8 \mathrm{~m}$ above the ground (approximately $1.4 \mathrm{~m}$ above the cows) over the whole area of the cooling yard. Each cooling session was 45 min long and consisted of nine cycles in which the cows received one-minute showers followed by four minutes of ventilation. The $3 x$ cool group received cooling before each milking time (i.e., 0415, 1215 and $1915 \mathrm{~h}$ ) three times per day. The $8 \mathrm{xcool}$ group received eight cooling sessions per day at $0100,0415,0930,1215,1445,1700,1915$ and $2200 \mathrm{~h}$, respectively. The 2nd, 4th and 7 th cooling sessions in the 8xcool group were followed by milking. For further cooling sessions, the $8 \times$ cool group was brought out five additional times between milking, while the $3 \times$ cool remained inside the cowshed without cooling.

All the cows were fed a total mixed ration and were milked three times daily at 0505,1305 and $2005 \mathrm{~h}$ in a double herringbone parlor with 13 places each side. 
The average daily milk yield of the herd was $44.23 \pm 7.70 \mathrm{~kg}$ (mean $\pm \mathrm{SD}$ ) per cow. The days in milk (DIM) were on average $128 \pm 64.9$ on the first experimental day. Days in milk were classified according to the lactation period (early: DIM $\leq 100$; middle: DIM $>100$ and $\leq 200$ and late: $\geq 201$ DIM). Milk yield per day and DIM were provided by the management software of the cowshed. Once a week, the health status (i.e., body temperature, heart rate and behavior) and body condition score of the cows were measured.

The coat color of every cow was determined from two digital photographs from both body sides of each cow using image analysis software (ImageJ version 1.51, Wayne Rasband NIH, Bethesda, MD, USA) as previously described by Kendall et al. (2007) and Tucker et al. (2008). Cows were categorized as having dark (mean \pm SD: $85 \pm 7.6 \%$ black hair), mixed $(59 \pm 8 \%$ black hair) or light $(19 \pm 4.8 \%$ black hair) coat color.

The trials comply with the supervision of the ARO Animal Care Committee (approval number $685 / 16$ IL). The animals were humanely treated during their day-today care by the farm staff and during the study.

\section{Environmental measurements}

Ambient temperature (AT) and relative humidity $(\mathrm{RH})$ of the air were recorded every 5 min with nine data loggers (EasyLog USB 2+, Lascar Electronics Inc., Whiteparish, England) positioned inside the buildings (seven in the cowshed and two in the cooling yard) 3 meters above the floor. A total of 109,793 climate datapoints were recorded during the measurement period. The temperature-humidity index (THI) was calculated according to NRC (1971) as follows:

$$
T H I=\left(1.8 \times T_{d b}+32\right)-(0.55-0.0055 \times R H) \times\left(1.8 \times T_{d b}-26\right)
$$

where:

$T_{d b}$ is the dry bulb temperature (in ${ }^{\circ} \mathrm{C}$ ),

and $R H$ is the relative humidity (in \%).

The sprinkler water temperature was measured directly on the water outlet nozzle twice daily with a digital thermometer (Fisher Inc., Pittsburgh, PA, USA). The average sprinkler water temperature was $25.5 \pm 1.7^{\circ} \mathrm{C}$ (mean $\pm \mathrm{SD}$; range: 22.3 to $\left.27.6^{\circ} \mathrm{C}\right)$.

\section{Animal observations}

The respiration rate (RR) of the cows was observed hourly in one of three time segments (i.e., 1500 to $0200 \mathrm{~h}, 0900$ to $1700 \mathrm{~h}$, or 0600 to $1400 \mathrm{~h}$ ), yielding 9 to 12 measurements per cow per day. According to Kabuga (1992), the RR was observed visually by counting right thoracoabdominal movements for thirty seconds and multiplying the value by two (documented as breaths per minute, bpm). The cows were randomly observed within the group. Body posture (standing and lying) was documented. When the cows moved to the cooling yard or back to the cowshed, 
a 15-min adaptation phase was provided before RR counting started. Observation time relative to cooling was classified as precooling (last observation in the cowshed before cooling), during cooling (all observations in the cooling yard) and post cooling (first observation after return to the cowshed).

\section{Statistical analysis}

All data collected during the experimental period were used for analysis. The analysis included a total of 4,686 RR observations in 20 cows. A linear mixed model with repeated measurements per cow to test the effect of treatment group (3xcool vs. 8xcool) on analyses of RR was performed. Fixed factors in the models as group and cow-related factors, such as body posture (standing vs. lying), daily milk yield, DIM class (early, middle and late) and coat color (dark, mixed and light), were included. All analyses were performed using SAS 9.4 (SAS Institute Inc., Cary, NC, USA). The model used was as follows:

$$
\text { Yijklm }=\mu+G R P_{i}+C O L_{j}+(P O S \times L O C)_{k}+D I M_{l}+a \cdot M Y+C_{i m}+\varepsilon_{i j k l m}
$$

where:

$Y$ is the dependent variable of the natural logarithm of the RR,

$\mu$ is the general mean,

$G R P$ is the effect of the $i$ th treatment group (3xcool, 8xcool),

$C O L$ is the effect of the $j$ th coat color,

$P O S$ is the effect of the $k$ th cow posture (standing or lying),

$L O C$ is location of the animals during the measurements (cooling yard or cowshed,

$P O C \times L O C$ is the effect of the $k$ th combination of cow posture and cow location,

$D I M$ is the effect of the $l$ th lactation period (early: DIM $\leq 100$;

middle: DIM $>100$ and $\leq 200$ and late: $\geq 201$ DIM),

$a$ is the regression coefficient for milk yield (MY),

$C$ is the random effect of the $m$ th cow in treatment group $i$,

$\varepsilon$ is the random residual.

A variance component covariance structure was used for random effects and repeated measurements. Factor influences were tested at a significance level of 0.05. The differences between the significant factors were post hoc tested by t-tests in multiple pairwise comparisons. The P-values of those multiple comparisons were adjusted by a simulation of the true $95 \%$-quantile of the contrasts, maintaining a global significance level of 0.05 . Model viability was checked by a visual examination of the residuals (homogeneity of variance and normality). Interactions of groups in the precooling, during cooling and post cooling phases of RR reaction were tested. The cooling effect (RR differences between cooling and precooling phases) and post cooling effect (RR differences between cooling and post cooling phases) were calculated. A linear regression analysis of the cooling effect and post cooling effect data was performed, and the effect of treatment group was considered. 


\section{Results}

\section{Environmental conditions}

The average THI calculated was $78.3 \pm 3.26$ (mean \pm SD). The average THI was $76.0 \pm 1.22$ at $0000 \mathrm{~h}$ and $82.3 \pm 1.11$ at $1200 \mathrm{~h}$. The daily averages of ambient temperature and THI during the experimental period are shown in Figure 1.

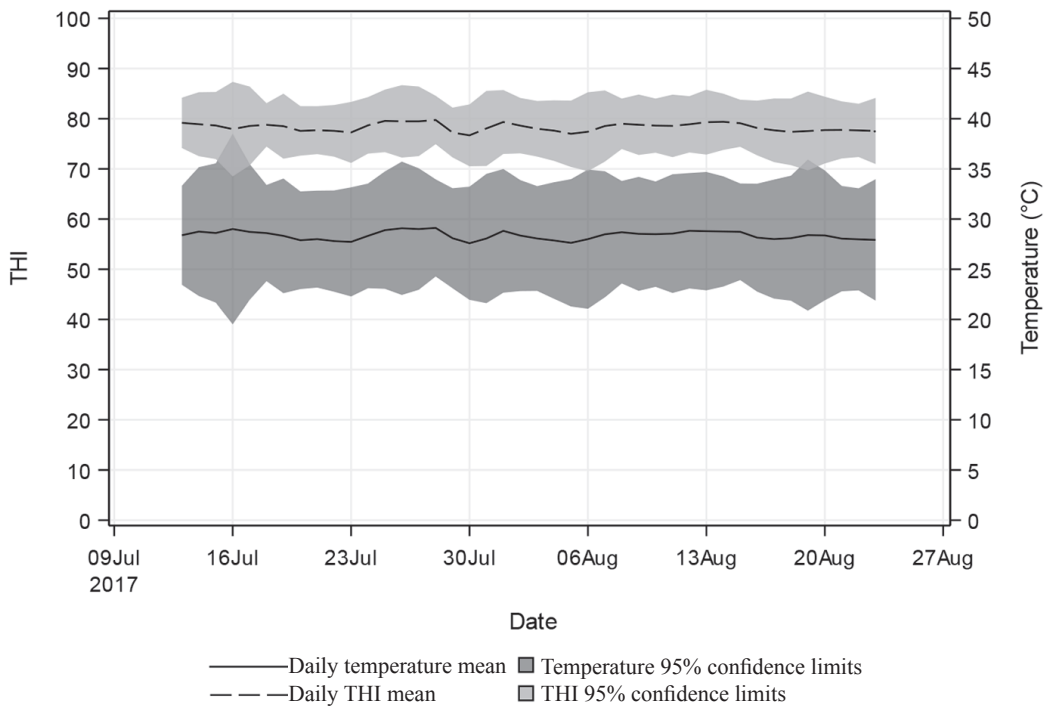

Figure 1. Daily average ambient temperature of the barn and temperature-humidity index (THI) during the experimental period (25 measurement days) from July to August 2016

\section{Influence of cooling frequency on respiration rate}

The RR differed between the 3xcool and 8xcool groups depending on cow body posture (standing and lying) and location (cowshed vs. cooling yard, $\mathrm{P}<0.001$ ). During the cooling time, cows remained in a standing posture. However, no differences in RR during the cooling period were observed between the 3xcool and 8xcool groups (Table 1).

Table 1. Least-square means of the respiration rate (mean $\pm \mathrm{SE}$ ) of standing and lying cows in the $3 \mathrm{xcool}$ and $8 \mathrm{xcool}$ groups in different places

\begin{tabular}{l|c|c|c|c|c|c}
\hline & \multicolumn{3}{|c|}{ Cowshed } & \multicolumn{3}{c}{ Cooling yard } \\
\cline { 2 - 7 } & $3 \times$ xcool & $8 x c o o l$ & P-value & $3 x$ cool & 8 xcool & P-value \\
\hline Body posture & & & & \\
Standing & $73.1 \pm 0.64$ & $60.2 \pm 0.72$ & $<0.001$ & $47.1 \pm 0.66$ & $43.9 \pm 0.37$ & NS \\
Lying & $65.6 \pm 0.65$ & $51.6 \pm 0.57$ & $<0.001$ & - & - & - \\
\hline
\end{tabular}

NS: No significant effect.

Significant test level $\mathrm{P}<0.05$. 


\section{Respiration rate of cows on precooling, cooling and post cooling phases}

The average RR was $77.9 \pm 0.59 \mathrm{bpm}, 43.6 \pm 0.51 \mathrm{bpm}$ and $56.2 \pm 0.54 \mathrm{bpm}$ during the precooling, cooling and post cooling phases, respectively. The RRs of each group in different cooling times and different phases of cooling are shown in Table 2.

Table 2. Respiration rate of cows (mean $\pm \mathrm{SE}$ ) in different measurement phases arranged by group and cooling number

\begin{tabular}{c|c|c|c|c|c}
\hline Group & Cooling number & Cooling time & Precooling & Cooling & Post cooling \\
\hline 3xcool & 1 & $0415-0500$ & $75.1 \pm 2.22$ & $37.3 \pm 1.14$ & $39.0 \pm 0.58$ \\
& 2 & $1215-1300$ & $92.6 \pm 1.15$ & $49.0 \pm 0.84$ & $60.4 \pm 1.21$ \\
& 3 & $1915-2000$ & $90.8 \pm 2.15$ & $42.6 \pm 1.29$ & $57.1 \pm 1.53$ \\
8xcool & 1 & $0100-0145$ & $71.2 \pm 1.64$ & $38.4 \pm 0.79$ & $45.6 \pm 1.01$ \\
& 2 & $0415-0500$ & $62.6 \pm 2.16$ & $36.6 \pm 0.92$ & $40.2 \pm 0.99$ \\
& 3 & $0930-1015$ & $74.6 \pm 1.25$ & $42.8 \pm 0.65$ & $56.4 \pm 1.17$ \\
& 4 & $1215-1300$ & $73.8 \pm 1.22$ & $44.9 \pm 0.82$ & $64.6 \pm 1.32$ \\
& 5 & $1445-1530$ & $85.0 \pm 1.61$ & $49.2 \pm 1.19$ & $71.4 \pm 2.25$ \\
& 6 & $1700-1745$ & $73.5 \pm 2.58$ & $44.2 \pm 1.69$ & $53.2 \pm 1.54$ \\
& 7 & $1915-2000$ & $73.2 \pm 2.29$ & $40.3 \pm 0.90$ & $61.0 \pm 1.45$ \\
P-value & 8 & $2200-2245$ & $61.0 \pm 1.45$ & $39.5 \pm 1.03$ & $42.3 \pm 1.25$ \\
\hline
\end{tabular}

$\mathrm{P}$-values indicate differences between $3 \mathrm{xcool}$ and $8 \mathrm{xcool}$ at a significant test level of $\mathrm{P}<0.05$.

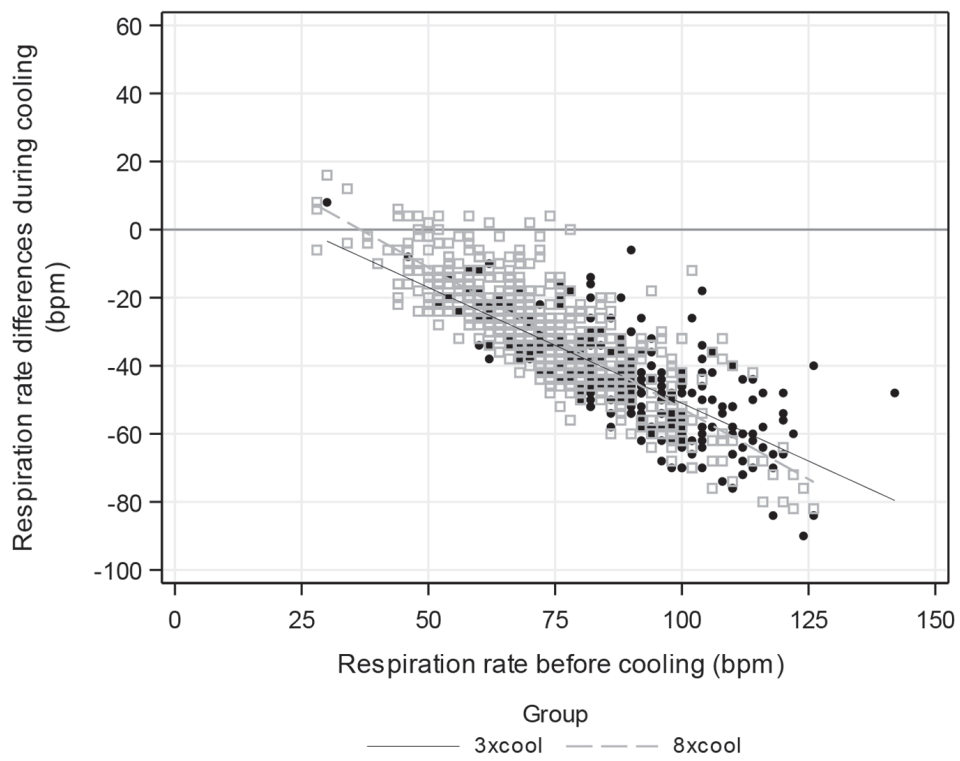

Figure 2. Differences in respiration rates (RR) between the precooling and cooling phases of 3xcool (black dots) and 8xcool (white squares) cows depending on the precooling RR 
During the precooling phase, the RR of $3 \times$ cool cows $(89.1 \pm 0.85 \mathrm{bpm}$, mean \pm $\mathrm{SE}$ ) was higher than the RR of $8 x$ cool cows $(73.1 \pm 0.56)$. There was no significant difference in RR between the 3xcool and 8xcool groups during the cooling (45.6 \pm 0.67 and $42.8 \pm 0.37$, respectively) and post cooling phases $(55.9 \pm 0.94$ and $56.3 \pm$ 0.65 , respectively).

Cows with high RR values during the precooling phase showed a large RR decrease during the cooling phase in both groups $(\mathrm{P}<0.001)$, but no differences in the cooling effect between the $3 \times$ cool and 8 xcool groups $(\mathrm{P}=0.1008)$ were observed (Figure 2). Cows of both groups with RRs over $50 \mathrm{bpm}$ during precooling showed a stronger RR decrease than did those with RRs under 50 bpm during the precooling phase.

In the analysis of the post cooling effect, cows with a high RR during cooling showed a small RR increase in the post cooling phase, and no differences between the $3 \times$ cool and $8 x$ cool groups were observed $(P=0.5595$, Figure 3$)$.

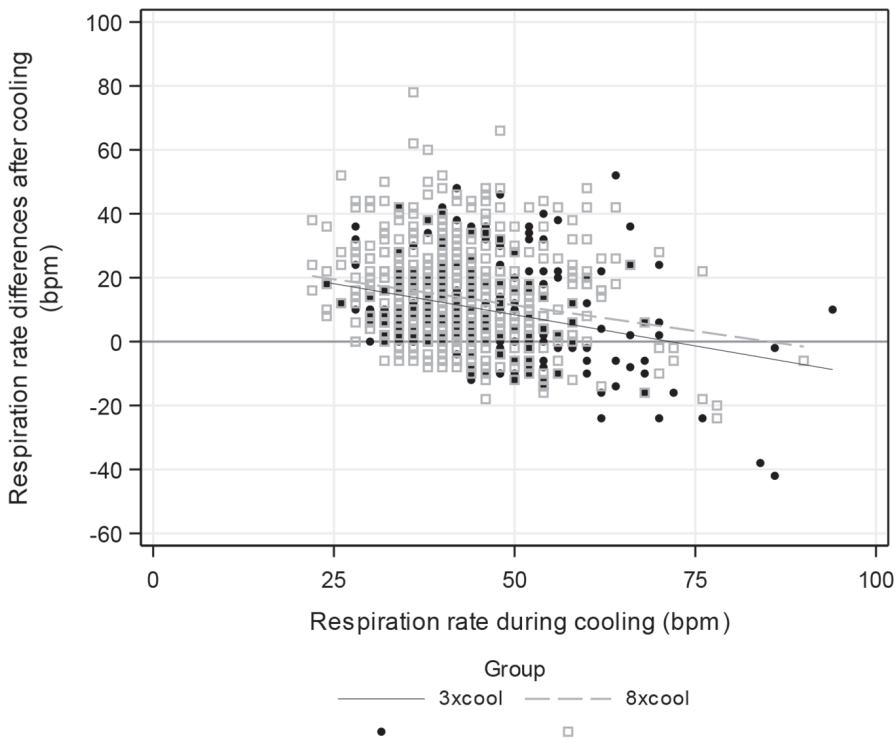

Figure 3. Differences in the respiration rate between the post cooling and cooling phases of $3 \times$ cool (black dots) and 8xcool (white squares) cows depending on the RR during the cooling phase

\section{Effects of cow-related factors on respiration rate}

The body posture showed significant influences on the RR of cows $(\mathrm{P}<0.001)$. The RRs of standing cows were 8 and $9 \mathrm{bpm}$ higher than those of lying cows in the $3 x$ cool and 8xcool groups, respectively (Table 1 ).

An increase in milk yield directly influenced the RR. With each additional $\mathrm{kg}$ of milk produced per day under hot conditions, the RR increased by $0.20 \mathrm{bpm}$ $(\mathrm{P}<0.001)$.

Cows in the early DIM period showed higher RR values $(71.3 \pm 0.98 \mathrm{bpm}$, mean $\pm \mathrm{SE})$ than cows in the middle DIM $(64.7 \pm 0.55 \mathrm{bpm})$ and cows in the late DIM $(59.0 \pm 1.23 \mathrm{bpm})(\mathrm{P}<0.001)$. 
There was no effect of coat color on the RR between the 3xcool and 8xcool groups $(\mathrm{P}=0.6213)$. The average $\mathrm{RR}$ of cows with dark, mixed and light coat color was $63.1 \pm 0.50,68.6 \pm 0.51$ and $64.1 \pm 0.72$, respectively.

\section{Discussion}

\section{Environmental conditions}

In the present study, the experimental barn was located in the coastal plain of Israel. The climate of this region is predominantly semi arid with a high relative humidity, and the study was conducted in what is typically the hottest season in Israel. The cows were constantly under moderate to severe heat stress with an average THI of 78. Our study corroborates the conditions described by Honig et al. (2012), who calculated a mean THI of 78 in the same location. At no time during the experimental period was the THI within the thermoneutral zone of cattle $(55 \leq \mathrm{THI} \leq 61)$ according to Garner et al. (2017).

\section{Relation between environmental conditions and respiration rate}

The average RR (62.6 bpm) of the cows inside the cowshed differed from that reported by Valtorta and Gallardo (2004) and by Kendall et al. (2007), who observed an average RR of $54 \mathrm{bpm}$ and $24 \mathrm{bpm}$, respectively, with both studies using evaporative cooling as the heat relief method. The THI of our study was higher than that in those studies. For example, in the study by Valtorta and Gallardo (2004), the average THI was 71, and Kendall et al. (2007) observed a THI ranging between 56 and 73 units, while we accepted a tendency of cows to show a high RR in the present study. This RR finding is also considered above the stress threshold between 50 and $60 \mathrm{bpm}$ defined by Berman et al. (1985). Even when we compared our results with those of a similar study carried out by Honig et al. (2012) under the same climate conditions and using eight cooling sessions per day, the RR (50 bpm) was lower than our findings in the present study.

\section{Influence of cooling sessions on respiration rate}

The results of the present study showed that 8xcool decreased the RR of dairy cows inside the cowshed, which is in accordance with the results obtained by Avendano-Reyes et al. (2010) and Honig et al. (2012). Avendano-Reyes et al. (2010), who compared different cooling management systems with three observations per week, observed that cows with two cooling sessions per day have a higher RR ( $9 \mathrm{bpm}$ in the morning and $5 \mathrm{bpm}$ in the afternoon) than do cows cooled in four sessions per day. Considering two different cooling frequencies, Honig et al. (2012) also observed a higher RR (6 bpm in the morning and $33 \mathrm{bpm}$ in the afternoon) in cows cooled in five sessions per day compared with cows cooled in eight sessions per day. In the present study, a higher RR (14 bpm, mean of different day times) was found in $3 \times$ cool cows than in $8 x$ cool cows. However, Honig et al. (2012) counted the RR twice per week (in the morning and afternoon), and our measurements were carried out hourly, as performed by Gaughan et al. (2008). 
The cooling was efficacious in reducing the RR of standing cows by approximately $36 \%$ (26 bpm) in the 3xcool cows and by approximately $26 \%$ (16 bpm) in the 8 xcool cows during the cooling phase compared with the RR in the precooling phase. The higher RR decrease in 3xcool cows was due to the higher RR values in the precooling phase of this group than in the 8xcool group, with a baseline of 47.1 $\pm 0.66 \mathrm{bpm}$ in $3 \times \mathrm{xcool}$ cows and $43.9 \pm 0.37 \mathrm{bpm}$ in $8 \mathrm{xcool}$ cows during the cooling phase. A similar RR baseline of approximately $47 \mathrm{bpm}$ during cooling was also observed in a previous study with steers (Gaughan et al., 2008). Other studies have demonstrated a reduction in RR due to cooling, where the cows with an average baseline RR of $88 \mathrm{bpm}$ before cooling showed a reduction of $13 \mathrm{bpm}$ after $48 \mathrm{~min}$ of cooling (Chen et al., 2015). Additionally, with 2 cooling sessions/day, a reduction of $23 \mathrm{bpm}$ after cooling application was described (Valtorta and Gallardo, 2004). In both studies, the RR of the cows was observed before and after the cooling process; hence, in our study, an additional measurement during the cooling took place.

Although no differences were observed in the RR between the 3xcool and 8xcool groups in the post cooling phase, the RR increment of the 8xcool cows was less than that of the $3 \times$ cool cows until the following cooling time, as also observed by Honig et al. (2012), who compared eight and five cooling sessions in dairy cows. The increase in the RR in the post cooling phase in both groups seemed to be a response to the high climate conditions that the animals were subjected to inside the barn, as also observed by Chen et al. (2015) after the cooling period. The RR increased from 8 to $40 \mathrm{bpm}$ two hours after cooling, related to the THI increase (Gaughan et al., 2008). Some authors have suggested that heat stressed cows may keep RR and body temperature below baseline during the cooling period and until $30 \mathrm{~min}$ post cooling (Flamenbaum et al., 1986; Chen et al., 2015), which is comparable to our study, where the RR of cows was determined an average of $53 \pm 0.12 \mathrm{~min}$ (mean $\pm \mathrm{SE}$ ) after the cooling phase, and the values were always above the baseline.

The positive effect of cooling on heat-stress relief in cattle is already clearly demonstrated in the literature (West, 2003; Ortiz et al., 2015; Fournel et al., 2017). In addition to this favorable effect of cooling on cows in the present study, we observed that 8 xcool cows experienced heat accumulation approximately two hours later than did 3xcool cows. Whereas the $3 \times$ cool cows reached a higher RR (92.6 bpm) at $1215 \mathrm{~h}$, the $8 x$ cool cows reached a higher RR $(85.0 \mathrm{bpm})$ before the session at $1445 \mathrm{~h}$. In those time sessions, the $3 \times$ cool cows showed a $44 \mathrm{bpm}$ abatement during cooling compared to the $36 \mathrm{bpm}$ reduction among the $8 \mathrm{xcool}$ cows. This result demonstrates a strong effect of cooling in cows with more cooling sessions per day, which prevents heat accumulation even during the hottest period of the day at $1200 \mathrm{~h}(\mathrm{THI}=82.3)$. These results are supported by other studies that observed an improvement in body temperature (Flamenbaum et al., 1986) and RR (Tresoldi et al., 2018) abatement with the increase in cooling exposure.

A benchmark for cooling frequencies in dairy cows is not concretely defined in the literature. Flamenbaum et al. (1986) concluded that five cooling sessions per day were sufficient to maintain low body temperatures in high-producing dairy cows. However, positive effects were also observed in body temperature and RR reduction of dairy cows with eight (Honig et al., 2012) and nine (Her et al., 1988) cooling ses- 
sions per day. We agree that eight cooling times per day improved the RR and heat stress abatement in dairy cows, with an average RR reduction of $14 \mathrm{bpm}$ in 8xcool cows compared to $3 \mathrm{xcool}$ cows in the present study.

\section{Effects of cow-related factors on respiration rate}

Body posture influenced the RR values in both groups. The RR of standing cows was on average 7 and $8 \mathrm{bpm}$ higher than the RR of lying cows in the 3xcool and 8 xcool groups, respectively. Previous studies also reported that body posture influences cows under heat stress conditions. The authors reported that heat stressed cows spend more time during the day standing to improve wind convection and hence increase body temperature dissipation (Frazzi et al., 2000; Tucker et al., 2008; Angrecka and Herbut, 2017). Although the lying posture in dairy cows is a good indicator of cow comfort (Acatincăi et al., 2010; Herbut and Angrecka, 2018), lying cows decrease approximately $42 \%$ of the body surface area exposed to air (Wang et al., 2018), and may show early heat stress conditions, even with a lower temperature threshold (Berman, 2005). According to our previous study, where the RR of cows in a lying posture was $7 \mathrm{bpm}$ higher than that of standing cows under a THI below 80 , the results of the present study differed. Standing and lying cows in the previous study showed no differences in RR when the THI was above 80 . We presume that the cows in the present study increased the RR in the standing posture to improve the effectiveness of heat relief by breathing and wind convection due to the hot environmental conditions over an extended period. Additionally, regarding the rate of each body posture (standing or lying) during the RR count, no differences between the 3 xcool and 8xcool groups were observed. Hypothetically, the 8xcool cows were expected to stand more often than the 3 xcool cows because they received more cooling sessions per day in a standing posture. Nonetheless, among all observations, $3 x$ cool cows spent $30 \%$ of their time in the standing posture, compared to $29 \%$ for the 8 xcool cows. We therefore presumed that the high standing posture rate in $3 \mathrm{xcool}$ cows was observed because they used their free time to improve heat dissipation, while the 8xcool cows used that free time for resting, as mentioned in other studies (Berman, 2006; Honig et al., 2012). In contrast to other studies that evaluated the influence of environmental temperature on milk yield losses (Ravagnolo et al., 2000; Moallem et al., 2010), we aimed to identify the influence of milk yield and DIM on the $R R$ reaction in heat-stressed cows. The RR increased one bpm over the average per five-kilogram of milk produced per day under heat stress conditions. We also determined that the RR of early lactation cows was $17 \%$ higher than that of cows in the late lactation period (DIM $\geq 201$ days). With these two cow factors, we assumed that cows with high milk production per day increased the RR in conditions of heat stress. A large energy demand for milk production during early to mid-lactation and associated cows under high THI conditions tend to increase the metabolic heat output (Hahn, 1999; Kadzere et al., 2002). High-producing cows have more heat to dissipate during the first 60 days of lactation (Sharma et al., 1983; West, 2003), which requires a particular management of cooling procedures to relieve the heat.

Our study demonstrated that coat color does not need to be considered during heat stress assessments as a cow-related factor in cows housed in a cowshed. In 
a study comparing cooled and non-cooled cows in pastoral systems, there were no differences in the average RR associated with coat color category, even in noncooled cows, which were constantly exposed to solar radiation (Kendall et al., 2007).

This study would be more powerful with an additional control group without cooling throughout the day, as published in other studies (Her et al., 1988; Valtorta and Gallardo, 2004; Chen et al., 2015 and 2016). During the summer in hot countries, however, failure to employ minimal cooling for high production cows directly impacts animal welfare and is not practicable in commercial barns (Honig et al., 2012). In addition, the ability to reduce heat load in cattle while reducing water consumption is an important issue for future studies in dairy production.

Under hot climate conditions, heat stressed cows lowered the RR by $14 \mathrm{bpm}$ when applied eight cooling sessions per day instead of three cooling sessions. The continuous measurements reduce the uncertainty of the heat stress assessment in dairy cows. The $8 x$ cool cows exhibited heat accumulation two hours later $(85.0 \mathrm{bpm}$ at $1445 \mathrm{~h}$ ) than $3 \mathrm{xcool}$ cows $(92.6 \mathrm{bpm}$ at $1215 \mathrm{~h})$. The RR of standing cows inside the cowshed was $8 \mathrm{bpm}$ higher than that of lying cows. For each additional five kilograms of milk produced, the respiration rate increased by one bpm. Additionally, cows in the early lactation period (DIM $\leq 100)$ tended to have a $17 \%$ higher RR than cows in the late lactation period. Our results suggest that eight cooling times per day improve the RR abatement in heat-stressed dairy cows under hot conditions. Further research is warranted to examine practices in water and energy consumption, labor expenditure, animal management and welfare that are suitable for cooling efficiency improvement.

\section{Acknowledgments}

The authors gratefully acknowledge the staff of the Department of Engineering for Livestock Management at the ATB Institute (Potsdam, Germany) and the staff of the experimental dairy farm at the Volcani Center (Bet Dagan, Israel) for their assistance with experimental setup and animal care. This project was funded by the "optimized animal-specific barn climatization facing temperature rise and increased climate variability" (OptiBarn) project of the FACCE ERA-NET Plus Initiative "Climate Smart Agriculture" in Brussels and by the "Projektträger Bundesanstalt für Landwirtschaft and Ernährung” (PTBLE - funding code: 315-06.01- 2814ERA02C) in Bonn and scholarship from the Coordination for Improvement of Higher Education Personnel - CAPES (Brazil).

\section{References}

A c at incăi S., Gavojdian D., St anciu G., Cziszter L.T., Tripon I., B a u 1 S. (2010). Study regarding rumination behavior in cattle - position adopted by cows during rumination process. Sci. Pap. Anim. Sci. Biotechnol., 43: 199-202.

A n g r e c k a S., H e r b u t P. (2017). Eligibility of lying boxes at different THI levels in a freestall barn. Ann. Anim. Sci., 17: 257-269.

Avendano-Reyes L., Alvarez-Valenzuela F.D., Correa-Calderon A., Algandar-Sandoval A., Rodriguez-Gonzalez E., Perez-Velazquez R., Macias - 
- Cruz U., Diaz-Molina R., Robinson P.H., F a del J.G. (2010). Comparison of three cooling management systems to reduce heat stress in lactating Holstein cows during hot and dry ambient conditions. Livest. Sci., 132: 48-52.

B e r m a n A. (2005). Estimates of heat stress relief needs for Holstein dairy cows. J. Anim. Sci., 83: $1377-1384$.

B e r m a n A. (2006). Extending the potential of evaporative cooling for heat-stress relief. J. Dairy Sci., 89: 3817-3825.

B erman A., Folman Y., Kaim M., Mamen M., Herz Z., Wolfenson D., Arieli A., Graber Y. (1985). Upper critical-temperatures and forced ventilation effects for high-yielding dairy cows in a sub-tropical climate. J. Dairy Sci., 68: 1488-1495.

B ernabucci U., La cetera N., B a umgard L.H., Rhoads R.P., Ronchi B., Nardone A. (2010). Metabolic and hormonal acclimation to heat stress in domesticated ruminants. Animal, 4: 1167-1183.

B rown-Brand 1 T.M., Eigen berg R.A., Ni en aber J.A., Hahn G.L. (2005). Dynamic response indicators of heat stress in shaded and non-shaded feedlot cattle, Part 1: Analyses of indicators. Biosyst. Eng., 90: 451-462.

Burgos R., Odens L.J., Collier R.J., B aumgard L.H., Van B a le M.J. (2007). Case study: evaluation of different cooling systems in lactating heat-stressed dairy cows in a semi-arid environment. The Professional Animal Scientist, 23: 546-555.

Chen J.M., S chutz K.E., Tucker C.B. (2015). Cooling cows efficiently with sprinklers: physiological responses to water spray. J. Dairy Sci., 98: 6925-6938.

Chen J.M., S chutz K.E., Tucker C.B. (2016). Cooling cows efficiently with water spray: behavioral, physiological, and production responses to sprinklers at the feed bunk. J. Dairy Sci., 99: 4607-4618.

F la menbaum I., Wolfen son D., Mamen M., B erman A. (1986). Cooling dairy cattle by a combination of sprinkling and forced ventilation and its implementation in the shelter system. J. Dairy Sci., 69: 3140-3147.

F ournel S., Ouellet V., Charbonneau E. (2017). Practices for alleviating heat stress of dairy cows in humid continental climates: a literature review. Animal, 7: 37; doi:10.3390/ani7050037.

Frazzi E., Calamari L., Calegari F., Stefanin i L. (2000). Behavior of dairy cows in response to different barn cooling systems. ASAE, 43: 387-394.

Galán E., Llon ch P., Villa grá A., Levit H., P in to S., de 1 Prado A. (2018). A systematic review of non-productivity-related animal-based indicators of heat stress resilience in dairy cattle. Plos One, 13: e0206520.

G a rne r J.B., D o u g l a s M., Will i a m s S.R.O., Wa le s W.J., M a r e t t L.C., D i G i a c o mo K., L e u r y B.J., H a y e s B.J. (2017). Responses of dairy cows to short-term heat stress in controlledclimate chambers. Anim. Prod. Sci., 57: 1233-1241.

G a u g h a n J.B., H o lt S.M., H a h n G.L., M a d e r T.L., E i g e n b e r g R. (2000). Respiration rateis it a good measure of heat stress in cattle? Asian-Australas. J. Anim., 13: 329-332.

G a u g h a n J.B., M a d e r T.L., H o lt S.M. (2008). Cooling and feeding strategies to reduce heat load of grain-fed beef cattle in intensive housing. Livest. Sci., 113: 226-233.

Hahn G.L. (1999). Dynamic responses of cattle to thermal heat loads. J. Anim. Sci., 77, Suppl 2: 10-20.

Her E., Wolfen son D., F la m en ba u m I., F olman Y., K a i m M., B e r m a n A. (1988). Thermal, productive, and reproductive responses of high yielding cows exposed to short-term cooling in summer. J. Dairy Sci., 71: 1085-1092.

H e r b u t P., A n g r e c k a S. (2018). The effect of heat stress on time spent lying by cows in a housing system. Ann. Anim. Sci., 18: 825-833.

Honig H., Miron J., Lehrer H., Jackoby S., Zachut M., Zinou A., Portnick Y., Mo a lle m U. (2012). Performance and welfare of high-yielding dairy cows subjected to 5 or 8 cooling sessions daily under hot and humid climate. J. Dairy Sci., 95: 3736-3742.

K a bu g a J.D. (1992). The influence of thermal conditions on rectal temperature, respiration rate and pulse-rate of lactating Holstein-Friesian cows in the humid tropics. Int. J. Biometeorol., 36: 146150 .

Ka d zere C.T., M ur phy M.R., S i l a n i k ove N., M a ltz E. (2002). Heat stress in lactating dairy cows: a review. Livest. Prod. Sci., 77: 59-91. 
Kendall P.E., Verkerk G.A., Webster J.R., Tucker C.B. (2007). Sprinklers and shade cool cows and reduce insect-avoidance behavior in pasture-based dairy systems. J. Dairy Sci., 90 : 3671-3680.

L e g a te s J.E., F arth ing B.R., C a s a dy R.B., B arrad a M.S. (1991). Body temperature and respiratory rate of lactating dairy cattle under field and chamber conditions. J. Dairy Sci., 74: 2491-2500.

M a i a A.S.C., d a S ilva R.G., B e rt i p a g li a E.C.A. (2005). Environmental and genetic variation of the effective radiative properties of the coat of Holstein cows under tropical conditions. Livest. Prod. Sci., 92: 307-315.

Moallem U., Altmark G., Lehrer H., Arieli A. (2010). Performance of high-yielding dairy cows supplemented with fat or concentrate under hot and humid climates. J. Dairy Sci., 93: 3192-3202.

Ortiz X.A., S mith J.F., Villar F., Hall L., Allen J., Oddy A., a l-Haddad A., Lyle P., C o 11 i e r R.J. (2015). A comparison of 2 evaporative cooling systems on a commercial dairy farm in Saudi Arabia. J. Dairy Sci., 98: 8710-8722.

Pinto S., Hoffmann G., Ammon C., Amon B., Heuwieser W., Halachmi I., Banh a z i T., A m on T. (2019). Influence of barn climate, body postures and milk yield on the respiration rate of dairy cows. Ann. Anim. Sci., 19: 469-481; doi:10.2478/aoas-2018-0053.

Polsky L., von Keys e rlingk M.A.G. (2017). Invited review: Effects of heat stress on dairy cattle welfare. J. Dairy Sci., 100: 8645-8657.

Ravagnolo O., Misztal I., Hoogenboom G. (2000). Genetic component of heat stress in dairy cattle, development of heat index function. J. Dairy Sci., 83: 2120-2125.

Sharma A.K., Rodriguez L.A., Mekonnen G., Wilcox C.J., Bachman K.C., Colli e r R.J. (1983). Climatological and genetic effects on milk composition and yield. J. Dairy Sci., 66: $119-126$.

Tres oldi G., Schutz K.E., Tucker C.B. (2018). Cooling cows with sprinklers: Spray duration affects physiological responses to heat load. J. Dairy Sci., 101: 4412-4423.

T u c k e r C.B., R o g e r s A.R., S c h u t z K.E. (2008). Effect of solar radiation on dairy cattle behaviour, use of shade and body temperature in a pasture-based system. Appl. Anim. Behav. Sci., 109: $141-154$.

Valt or t a S.E., G a 11 a r d o M.R. (2004). Evaporative cooling for Holstein dairy cows under grazing conditions. Int. J. Biometeorol., 48: 213-217.

Wang X.S., Zhang G.Q., Choi C.Y. (2018). Effect of airflow speed and direction on convective heat transfer of standing and reclining cows. Biosyst. Eng., 167: 87-98.

We s t J.W. (2003). Effects of heat-stress on production in dairy cattle. J. Dairy Sci., 86: 2131-2144.

Received: 26 XI 2018

Accepted: 26 III 2019 